\title{
Persistent donor derived Vठ4 T cell clones may improve survival for recurrent $T$ cell acute Iymphoblastic leukemia after HSCT and DLI
}

\author{
Ling $\mathrm{Xu}^{1, *}$, Jianyu Weng ${ }^{2, *}$, Xin Huang ${ }^{2}$, Chengwu Zeng ${ }^{1}$, Shaohua Chen ${ }^{1}$, Suxia \\ Geng ${ }^{2}$, Lijian Yang ${ }^{1}$, Suijing Wu ${ }^{2}$, Suming Huang ${ }^{4}$, Xin Du² and Yangqiu Li ${ }^{1,3,5}$ \\ ${ }^{1}$ Institute of Hematology, Jinan University, Guangzhou, China \\ 2 Department of Hematology, Guangdong General Hospital, Guangdong Academy of Medical Sciences, Guangzhou, China \\ ${ }^{3}$ Key Laboratory for Regenerative Medicine of Ministry of Education, Jinan University, Guangzhou, China \\ ${ }^{4}$ Department of Biochemistry and Molecular Biology, University of Florida, Gainesville, Florida, USA \\ ${ }^{5}$ Department of Hematology, First Affiliated Hospital, Jinan University, Guangzhou, China \\ * These authors have contributed equally to this work \\ Correspondence to: Yangqiu Li, email: yangqiuli@hotmail.com \\ Xin Du, email: miyadu@hotmail.com
}

Keywords: T-ALL, T cell repertoire, allo-HSCT, MRD, DLI, Immunology and Microbiology Section, Immune response, Immunity Received: April 10, 2016

Accepted: June 13, 2016

Published: June 23, 2016

\section{ABSTRACT}

The outcome for T-cell acute lymphoblastic leukemia (T-ALL) in relapse after hematopoietic stem cell transplantation (HSCT) is quite poor, while, both donor lymphocytes infusion (DLI) and adoptively infusion of y $\delta$ T cells in leukemia patients after HSCT have demonstrated good results in prolonging survival time of patients. Here, we reported a T-ALL case who experienced three relapses and received HSCT and DLI with an overall survival (OS) time lasting for more than seven years. Based on our previous identification of a leukemic and reactive clone in this patient, continual y $\delta \mathrm{T}$ cell repertoire monitoring affirmed that the same Vठ5 leukemic clone existed in most samples from the patient, particularly including a sample taken at the time of the third T-ALL relapse, while it could not be detected in the donor sample. In addition, an identical $\mathrm{V} \delta 4$ monoclonal $\mathrm{T}$ cell that proliferated in the recipient for several years was confirmed to come from the donor graft, and its expression level significantly increased in third leukemia recurrence. These results indicate that clonally expanded Vठ4 $\mathrm{T}$ cells may represent a reconstituted yठ T cell repertoire after HSCT, which also hints to a relatively better outcome for this case. Based on this case study, we recommend DLI should be as a treatment strategy for patients who achieve CR or relapse from HSCT. Moreover, dynamically monitoring the TCR repertoire in patients who receive HSCT will benefit in supervising of malignant clone evolution and residue, identifying $T$ cell clones mediate anti-infection, GvHD or GvL.

\section{INTRODUCTION}

T-ALL in relapse is regarded as a practically incurable disease. Although a second completed remission (CR) may be achieved, the median disease-free survival (DFS) for this disease is dismal, but HSCT and DLI may be alternative methods for improving the survival of patients with relapse [1-3]. Here, we report a rare case who experienced three relapses with an overall survival lasting greater than seven years.
In a previous study, we reported a 25 -year-old male patient diagnosed with T-ALL on March 2008 who achieved hematological completed remission (CR1) after one course of chemotherapy followed by four courses of consolidation chemotherapy. In November 2009, the patient presented at the Department of Hematology, Guangdong General Hospital and was diagnosed with T-ALL relapse (RE1).

After being admitted in December 2009 with a recurrent T-ALL diagnosis, the patient received three 
courses of salvage chemotherapy lasting for three months (specific therapy protocols are shown in Figure 1); however, his response assessments were partial remission (PR), minor remission (MR), and MR respectively. Considering the poor prognosis for relapse T-ALL [2], the patient received an HLA-identical sibling peripheral blood (PB) HSCT on March 2010. Fifteen days after HSCT, a second complete remission was achieved (CR2). Short tandem repeat (STR) analysis revealed a 100\% donor chimera. Four weeks after HSCT, the patient suffered grade IV skin acute GvHD (aGvHD), which was ultimately controlled with methylprednisolone (MP) and cyclosporin (CsA) treatment at eight weeks post-HSCT [4]. Central nervous system leukemia (CNSL) was found 20 weeks post-HSCT; thus, intrathecal chemotherapy and radiotherapy of the head were then applied [5]. The patient continued CR2 and remained normal upon cerebrospinal fluid examination at 40, 52, and 68 weeks post-HSCT. However, relapse (RE2) was detected again 100 weeks after HSCT, approximately 33.5\% lymphoblasts revealed in bone marrow (BM). After receiving chemotherapy over the next two months, the patient achieved his third remission (CR3; 108 weeks post HSCT) with minimal residual disease (MRD) detected by flow cytometry (FCM).

Except the standard clinical and laboratory examination, to characterize the leukemia T cell clone, we used the fine-tiling comparative genomic hybridization (FT-CGH), ligation-mediated polymerase chain reaction (LM-PCR), real-time PCR (RT-PCR), GeneScan and sequencing techniques and identified the T-ALL clone, which included a monoclonally expanded TCR V $\delta$ subfamily member with a $\mathrm{V} \delta 5-\mathrm{D} \delta 2-\mathrm{J} \delta 1$ rearrangement [6]. This molecular characteristic provide a useful maker for monitoring the prognosis of this case. We also simultaneously identified a clonally expanded reactive

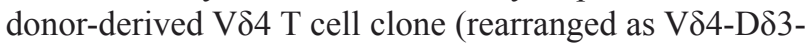
$\mathrm{J} \delta 1$ ) that existed in all samples from the recipient postHSCT, which may function as an anti-leukemia $\mathrm{T}$ cell clone that may improve patient survival.

In this study, we continually monitored the TCR $\gamma \delta$ repertoire in this patient from 117 weeks post-HSCT until the patient died at 274 weeks post-HSCT due the third relapse (RE3/the second relapse post-HSCT).

Based on careful analysis and dynamically monitoring the TCR $\gamma \delta$ repertoire in this patient, we tried to sum up our experience with recurrent T-ALL therapy by evaluating information from dynamic TCR $\gamma \delta$ repertoire monitoring.

\section{RESULTS}

\section{Treatment after HSCT and disease progression}

For the purpose of eradicating MRD, instead of receiving adjuvant chemotherapy, the patient received 3 donor lymphocyte infusions (DLIs) at 117, 120 and 124 weeks post-HSCT (Figure 1), and IFN- $\gamma$ and IL-2 were given to enhance the DLI effects. At week 129.5 post HSCT, the patient underwent mild cGvHD (Grade I of mouth), so IL-2 was ceased, and the frequency of IFN- $\gamma$ was adjusted to once per month. At week 146 post-HSCT, the mild cGvHD progressed to moderate cGvHD (Grade

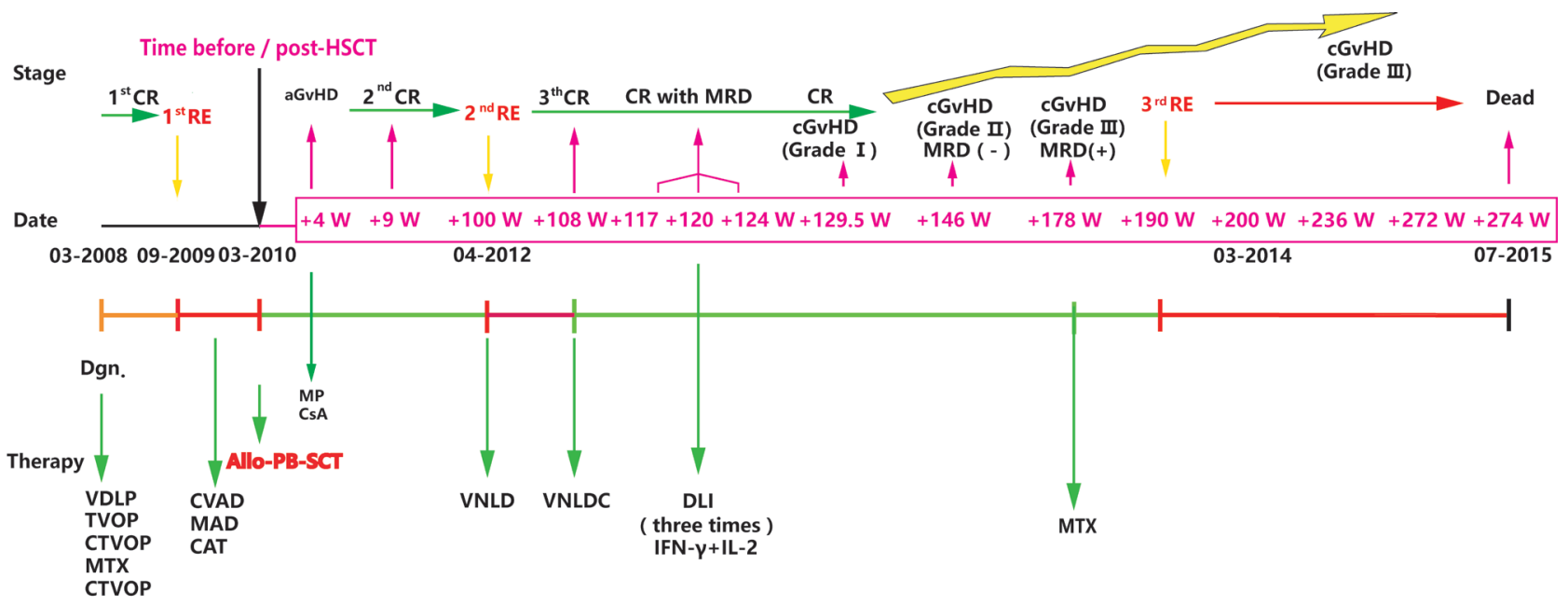

Figure 1: Disease time course of the reported T-ALL case. The key dates: initial diagnosis, first time of relapse (RE1), allo-HSCT, RE2 and RE3 are depicted in the middle of the graph. The disease stages: remission or relapse with or without GvHD are shown above the graph, and the type of administered therapy is presented below the graph. Notes: VDLP (V: vineristine, D: daunorubicin, L: L-asparaginase, P: prednisone), TVOP (T: Pirarubicin/THP, V: etoposide, O: vincristine, P: prednisone); CTVOP(C: cyclophosphamide and TVOP ); MTX: methotrexate; CVAD (C: cyclophosphamide, V: vincristine, A: adramycin and D: dexamethasone); MAD (M: Methotrexate, A: Ara-c/ cytarabine, D: dexamethasone); CAT (C: cyclophosphamide, A: Ara-c/cytarabine, T: topotecan), VNLD (V: Vindesine, N: mitoxantrone, L: L-asparaginase, D: dexamethasone), VNLDC (VNLD and C: cyclophosphamide); Allo-PB-SCT: allogeneic peripheral blood stem cell transplantation; CR: complete remission; MRD: minimal residual disease. 
Table 1: Sample collection dates and clinical patient characteristics

\begin{tabular}{|c|c|c|c|c|}
\hline $\begin{array}{l}\text { Collection } \\
\text { Date }\end{array}$ & Diagnosis & $\begin{array}{l}\text { Smear analysis } \\
\text { Blast cells (\%) } \\
\text { In BM / PB } \\
\end{array}$ & $\begin{array}{l}\text { MRD analyzed } \\
\text { by } \\
\text { FCM }\end{array}$ & Disease Statuses \\
\hline 31.08 .2012 & Donor & & & \\
\hline 14.08.2012 & $117 \mathrm{~W}$ post allo-HSCT & $3 / 0$ & $2.55 \%$ & CR, before DLI \\
\hline 31.08 .2012 & $120 \mathrm{~W}$ post allo-HSCT & $3 / 0$ & $6.36 \%$ & CR, before DLI \\
\hline 19.12.2012 & $135 \mathrm{~W}$ post allo-HSCT & $3 / 0$ & NA & CR, Grade I cGvHD \\
\hline 05.02 .2013 & $142 \mathrm{~W}$ post allo-HSCT & $2 / 0$ & NA & CR, Grade I cGvHD \\
\hline 05.03 .2013 & 146W post allo-HSCT & $2 / 0$ & NA & CR, Grade II cGvHD \\
\hline 16.10 .2013 & $178 \mathrm{~W}$ post allo-HSCT & $2 / 0$ & $0.14 \%$ & CR, Grade II cGvHD \\
\hline 14.01.2014 & 190W post allo-HSCT & $8 / 1$ & $3.81 \%$ & $\begin{array}{l}\text { Relapse,Grade } \\
\text { cGvHD }\end{array}$ \\
\hline 25.03 .2014 & $200 \mathrm{~W}$ post allo-HSCT & $90 / 14$ & $87.78 \%$ & $\begin{array}{l}\text { Relapse,Grade } \\
\text { cGvHD }\end{array}$ \\
\hline 14.10.2014 & $236 \mathrm{~W}$ post allo-HSCT & NA & NA & $\begin{array}{lll}\begin{array}{l}\text { Relapse, } \\
\text { cGvHD }\end{array} & \text { Grade } & \text { III } \\
\end{array}$ \\
\hline 14.07 .2015 & $272 \mathrm{~W}$ post allo-HSCT & $96 / 97$ & $96.67 \%$ & $\begin{array}{l}\text { Relapse, Grade III } \\
\text { cGvHD }\end{array}$ \\
\hline 27.07 .2015 & $274 \mathrm{~W}$ post allo-HSCT & & & Died \\
\hline
\end{tabular}

Notes: NA: Not analyzed, CR: complete remission, MRD: minimal residual disease, DLI: donor lymphocyte infusion, cGVHD: chronic graft versus host disease.

II with skin). At week 178 post HSCT, the patient suffered severe cGvHD (Grade III of skin, sclerosis-like), FCM analysis revealed MRD with $0.14 \%$ blast cells, while $2 \%$ blast cells were detected in the BM by a marrow aspirate smear (BMAS). Thus, we ceased the IFN- $\gamma$ therapy and used methotrexate (MTX) (10 mg q.w.) for cGvHD treatment. At week 190 post-HSCT, the patient was diagnosed with T-ALL relapse (RE3) with BMAS demonstrating $8 \%$ lymphoblast. At 200 -week post-HSCT, lymphoblast were increased to $90 \%$ in BM and $14 \%$ in PB. However, what was interesting is that the severe cGvHD continued to exist even after the patient underwent an obvious relapse. Finally, the patient refused to receive further chemotherapy and died at 274 weeks post-HSCT (July 28, 2015). The treatment used and efficacy are summarized in Figure 1 and the MRD monitoring FCM figure is provided as Supplemental Figure 1.

\section{TCR $\gamma \delta$ repertoire monitoring of leukemic and donor-derived $T$ cell clones}

The patient achieved an extended disease-free survival time from $\mathrm{CR} 3$ to the time before the third leukemia recurrence, which lasted 82 weeks. We continually monitored the dynamic changes in the TCR V85 subfamily in this case at different time points from CR3 to the endpoint before the patient died $(117,120,135$,
142, 146, 178, 190, 200, 236 and 272 weeks post-HSCT respectively), and the TCR $\gamma$ and $\delta$ repertoires of the donor samples were also analyzed at the same time. Sample collection dates and disease statuses are shown in Table 1.

The leukemic V85 T cell clone, which we previously identified at the time of diagnosis, could be detected in all of the recipient samples with exception for one collected at 178 weeks post-HSCT when the patient was in CR status (Figures 1 and 2) with $0.14 \%$ blast cells in the BM (Table 1). As expected, this V $\delta 5$ leukemic clone could not be detected in the donor sample (Figure 2), indicating that this oligoclonal V85 clone (with same CDR3 length, PCR products: $466 \mathrm{bp}$ ) did not come from the donor, and it appeared with disease relapse and disappeared or decreased with disease remission. The oligoclonally expanded V $\delta 4$ subfamily $\mathrm{T}$ cell clone (V84-D $\delta 3-J \delta 1$; Figure 3B), which was detected in all samples post-HSCT $(4,8,68,100$, and 108 weeks), but not in the sample before HSCT [1], was also detectable in all samples in this study with the exception of the sample (272 weeks post-HSCT) collected before the patient died (Figure 2). Direct sequencing confirmed that all of the CDR3s of the oligoclonally expanded $\mathrm{V} \delta 4+$ subfamily rearranged in the same pattern and were consistent with those previously detected (Figure 3). Interestingly, the same monoclonal $\mathrm{V} \delta 4$ clone was also identified in donor sample collected at the time for DLI. The CDR3 sequence of the V 84 clone in donor sample was confirmed to be consistent with that in 


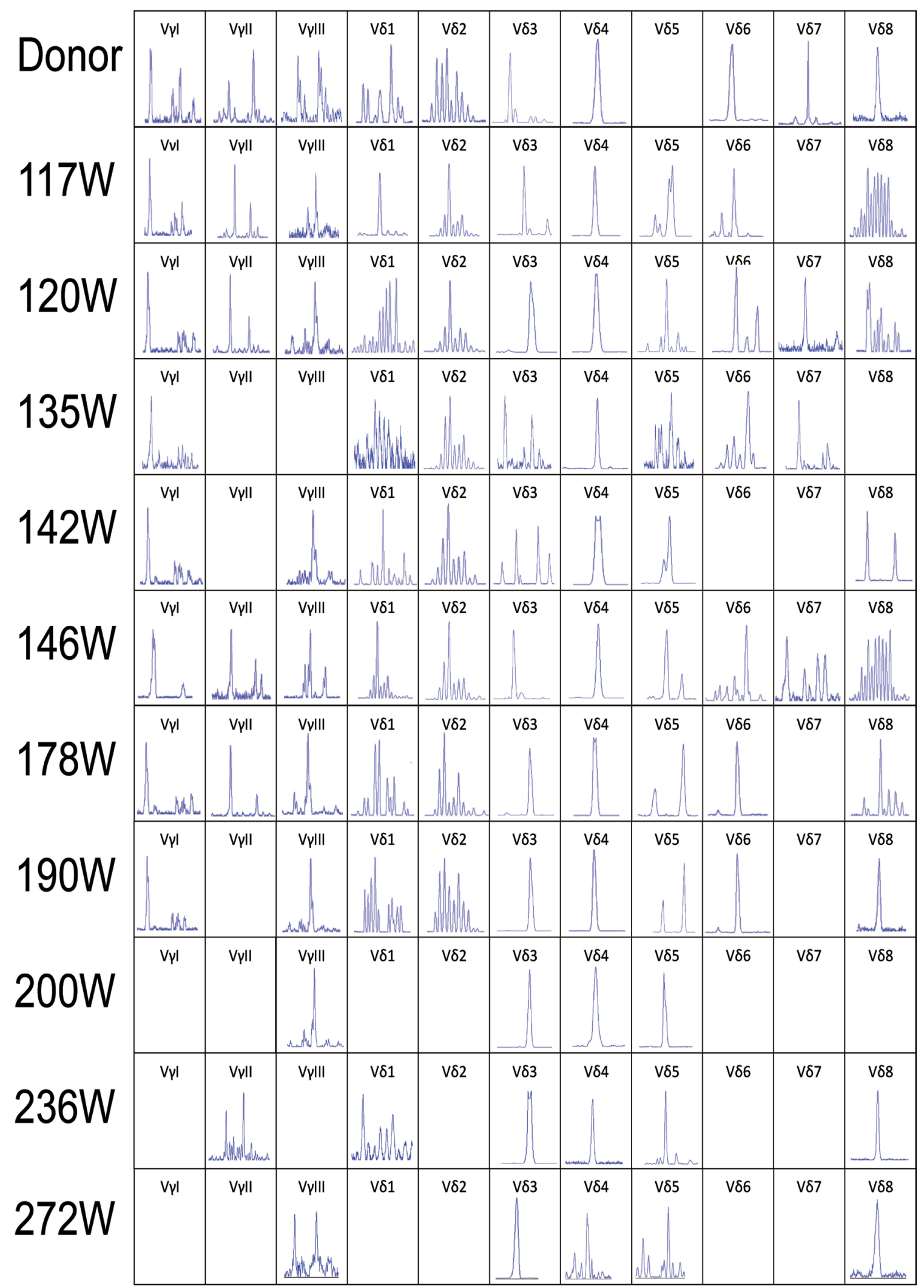

Figure 2: CDR3 spectratyping of the TCR $V \gamma$ and $V \delta$ subfamily $T$ cells in peripheral blood from the donor and recipient (117 to 272 weeks post-HSCT) at different time points after allo-HSCT. The 466bp V $\delta 5$ clone was not detected in the donor sample and the recipient sample in 178 weeks post-HSCT, the same size V 84 monoclone could be detected in the donor and recipient samples in all time points post-HSCT. All the V $\delta 3, \mathrm{~V} \delta 4$ and V $\delta 5$ clones detected in the same size are shown in the same position in horizontal axis. CDR3, complementarity determining region 3. 
the recipient (Figure 3A). In addition, the V $\delta 4$ expression level was significantly increased to a new peak at the time of RE3 (200 weeks post-HSCT), and it was undetectable in the next two samples (236 and 272 weeks post-HSCT). The V 84 expression level in the PBMC and BMC samples at different time points are shown in Figure 4. Moreover, the dynamic changes in the TCR V $\delta 3$ subfamily attracted our attention, clonally expanded V $\delta 3 \mathrm{~T}$ cells with a 508 bp (PCR products) was identified in the donor sample can be also detected a monoclonal expansion in the recipient samples in 117,135 and 142 weeks post-HSCT, while another $\mathrm{V} \delta 3 \mathrm{~T}$ cell clone with a $526 \mathrm{bp}$ (PCR products) was detected in the patient sample pre-HSCT (RE1) and several samples after-HSCT, but not exist in the donor sample, and had been identified in the same sequence (Figure 2). The evolution of V83 T cell clone depicted in Figure 5 and Supplemental Figure 2. The evolution of $\gamma \delta \mathrm{T}$ cell clones from both donor and recipient are summarized in a schematic figure (Figure 5).

\section{DISCUSSION}

The disease process of this T-ALL case from the time of initial diagnosis to the final relapse can be divided into three phases: initial diagnosis to $\mathrm{CR} 1$ and then undergoing RE1 (Phase 1), treatment with allo-HSCT to achieving CR2 and then undergoing RE2 (Phase 2), treatment with salvage chemotherapy and achieving CR3 followed by death due to RE3 (Phase 3). It is well known that leukemic relapse in adult ALL remains a major therapeutic challenge. The outcome for recurrent T-ALL is quite dismal with only $5 \%$ having a 5 year overall survival (OS) [7]. For the patient in this study, the common chemotherapy used allowed him to achieve remission. Unfortunately, disease recurrence could not be controlled with salvage chemotherapy. As several clinical trials have demonstrated, for patients who have not already been treated with HSCT, the achievement of a second remission is usually followed by high-dose chemotherapy and HSCT because it is typically regarded as the only potentially curative therapeutic option and the main goal of treatment after relapse [7-10]. However, the patient relapsed at 100 weeks post-HSCT (RE2), VDLP (vineristine, daunorubicin, L-asparaginase and prednisone) regimen help the patient achieved CR3, but MRD could be detected, which was thought to be a risk for relapse; therefore, DLIs were used to reduce the leukemic cells. Significantly, the MRD was controlled by this useful adoptive immunotherapy, and the patient successfully remained in CR3 for 20 months before the leukemia relapsed again at 190 weeks (RE3) post-HSCT. These results indicate that using DLI to eradicate residual leukemic clones in T-ALL patient after HSCT is quiet useful and helpful for prolonging the survival of patients

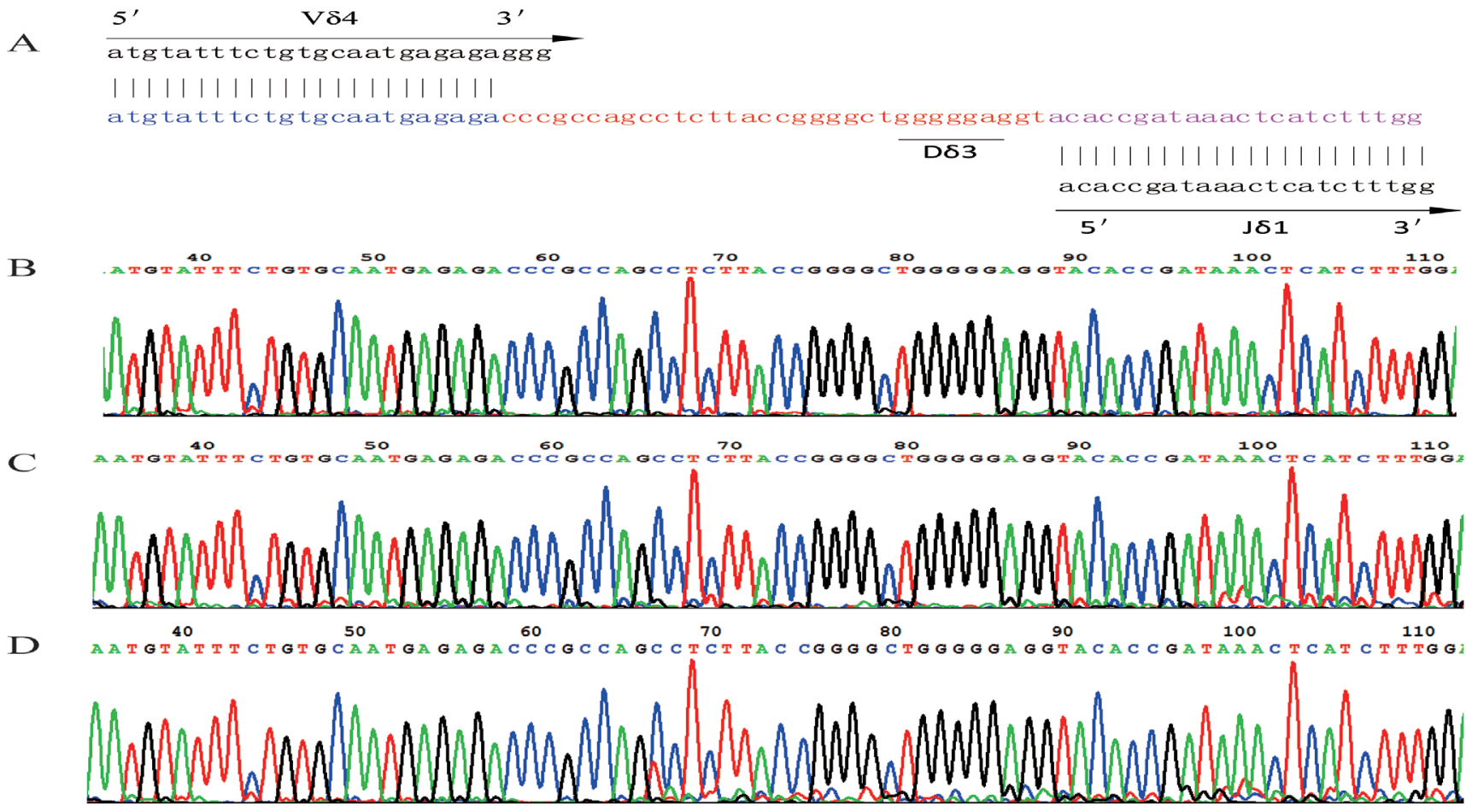

Figure 3: The nucleotide sequence of the V84 CDR3 region. A. The sequence of the V $84 \mathrm{CDR} 3$ region in the donor that rearranged as V $\delta 4-\mathrm{D} \delta 3-J \delta 1$. B. The sequence of V $\delta 4$ CDR3 region of recipient at 4 weeks post-HSCT. C. The sequence of V $44 \mathrm{CDR} 3 \mathrm{region}$ in recipient at 120 weeks post-HSCT. D. The sequence of V 84 CDR3 region in recipient at 190 weeks post-HSCT. CDR3, complementarity determining region 3 . 
and preventing leukemia recurrence. Allen et al. reported similar results in a study in which DLI successfully controlled MRD and led to a disease-free survival of more than 3 years for a 9-year-old T-ALL patient [11]. These results indicate that DLI may be used as a common strategy for T-ALL patients with MRD after HSCT. Even after undergoing RE3, the OS time of the patient was much longer than expected. The long-term disease remission of this patient and serial DLI treatment after achieving a third CR with persistent cGvHD were signals reflecting that an immune response was mediated by the grafts or the infusion of cells from the donor $[12,13]$. However, as we knew, there were also examples that DLI was failed to rescure patients with relapse leukemia after HSCT. The mechanism of the DLI which could successfully control the malignant leukemia clone in this case is worthy to characterize. In this study, we will discuss the clinical status combined with the immune effects detected by dynamic TCR repertoire monitoring in the following section in the hope that this will deepen our understanding of the underlying immunological mechanisms involved in this process.

The identification of leukemic $\mathrm{T}$ cell clones at the

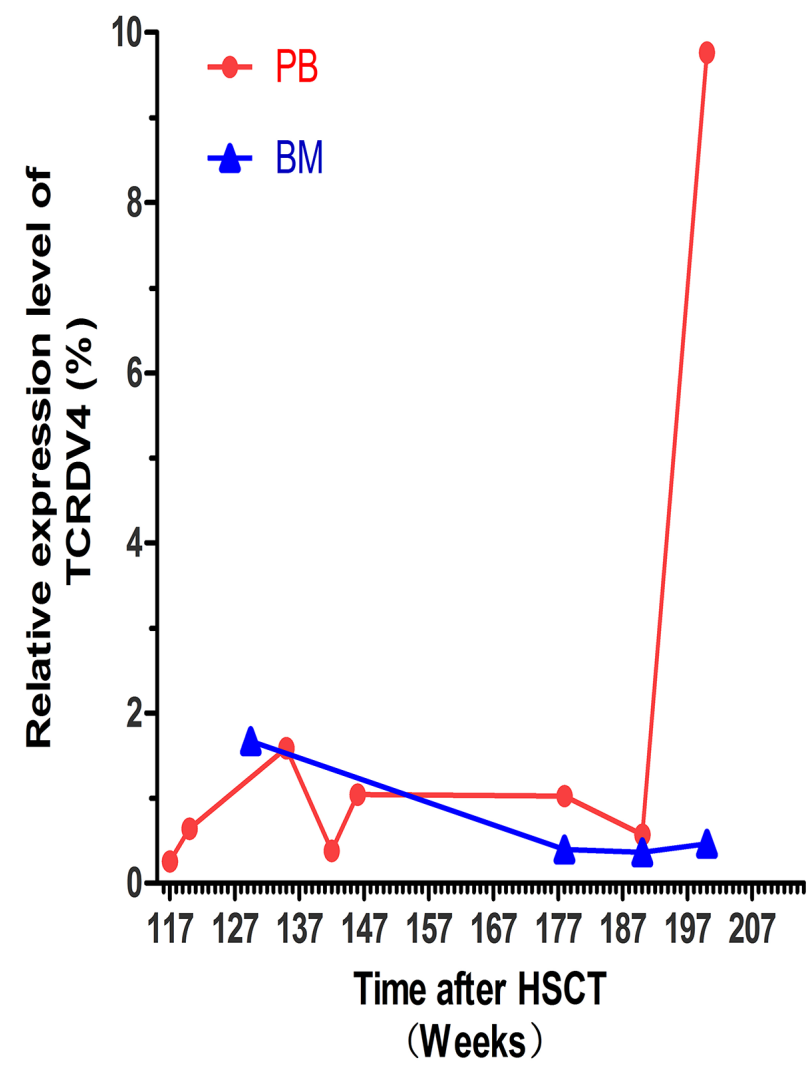

Figure 4: The TCR V 84 expression level in the recipient at different time point post-HSCT. The red dots indicate the expression level of the TCR V 84 (TCDV4) gene in PBMCs at the $117 \mathrm{~W}, 120 \mathrm{~W}, 135 \mathrm{~W}, 142 \mathrm{~W}, 146 \mathrm{~W}, 178 \mathrm{~W}, 190 \mathrm{~W}$ and $200 \mathrm{~W}$ time point post-HSCT. The blue triangles show the expression level of the TCR V 84 genes in the bone marrow (BM) at the $129.5 \mathrm{~W}, 178 \mathrm{~W}, 190 \mathrm{~W}$ and $200 \mathrm{~W}$ time point post-HSCT. time of diagnosis is important for evaluating disease remission, MRD, relapse and the possibility of clonal evolution in $\mathrm{T}$ cell malignancies. There are few studies reported the distribution of different $\mathrm{V} \delta$ subfamily leukemia, in previous studies, we identified two T-ALL cases with V $\delta 1$ and V $\delta 2$ bi-malignant T cell clones [14]. Based on the leukemic clone we identified at the initial time of disease and by monitoring the TCR repertoire in this case, the monoclonally expanded TCR V $\delta 5$ subfamily with the V $\delta 5-\mathrm{D} \delta 2-\mathrm{J} \delta 1$ rearrangement sequence was considered to be a component of the leukemic cell in this case together with the TCR V $\gamma \mathrm{I}$ subfamily. This stable V $\delta 5$ $\mathrm{T}$ cell clone indicated that this patient developed $\gamma \delta$ T cell leukemia, which is rare compared with $\alpha \beta \mathrm{T}$ cell leukemia, representing approximately $10 \%$ of T-ALL cases. Moreover, even for $\gamma \delta$ T-ALL, most leukemic T cells are largely expressed with limited $\mathrm{V} \delta 1-\mathrm{J} \delta 1$ rearrangements as reported by Langerak et al. who showed only 6 of $30 \gamma \delta$ T-ALL expressed non-V $\delta 1$ [15]. Comparison of the non-V $\delta 1+$ TCR $\gamma \delta$ T-ALLs with the more common $\mathrm{V} \delta 1+$ type revealed a heterogeneous mixture with respect to the immunophenotypic markers (e.g., CD1, CD4 and CD8, which are often expressed by non-V $\delta 1+$ TCR $\gamma \delta$ T-ALLs). In addition, a higher frequency of complete TCR $\delta$ and TCR $\beta$ rearrangements and 'end-stage' Jg2.3 gene rearrangements are often detected in non-V $\delta 1+\mathrm{TCR}$ $\gamma \delta$ T-ALLs, and these suggest a non-V $\delta 1$ TCR $\gamma \delta$ T-ALL trend toward more mature immunophenotypes compared with $\mathrm{V} \delta 1+$ types. The immunophenotypic markers we reported for this V $\delta 5+\mathrm{T}-\mathrm{ALL}$ case did not include CD1, CD4 or CD8. However, this patient expressed CD13, which is a marker that might suggest higher relapse risk compared with CD13- T-ALL cases [9]. Further analysis of TCR $\beta$ and 'end-stage' Jg2.3 gene rearrangements in the leukemic clone may help clarify the deterioration stage of this T-ALL patient. In addition, comparing the surface markers expressed between $\mathrm{V} \delta 1+\mathrm{T}-\mathrm{ALLs}$ and non-V $\delta 1+$ TCR $\gamma \delta$ T-ALLs may provide useful information for predicting the prognosis of these patients. In this study, the V $\delta 5$ leukemic clone represented when disease relapsed, we did not determine the leukemic clone evolution with other $\mathrm{V} \delta$ subfamily by monitoring TCR repertoire based on clonal expansion status. Obvious, most V $\delta$ subfamily $\mathrm{T}$ cells could be detected in most samples at the time point from 117 to 190 weeks, however, polyclonal expansion or oligoclonally expanded T cells with different CDR3 lengths indicated that came from different clones and would be the unspecific expansion. This T cell expansion may be enhanced by IL- 2 and IFN- $\gamma$ which were used with DLI [16, 17]. However, even the relapse with the same V $\delta 5$ leukemic clone, whether there was evolution in another molecule that may affect the biological behavior of a leukemic clone remains unclear, this may be identified by deep sequencing of the patient samples, which were collected at each instance of disease recurrence [18-20].

The DLI treatment had a positive effect on 
controlling the minor leukemic clone in this case, which prompted our interest in whether there was any antileukemia clone proliferation in the recipient after HSCT. Previously, we detected a monoclonally expanded V $\delta 4$ $\mathrm{T}$ cell clone in the patient samples after, but not before HSCT. Interestingly, we detected this same clone not only in the recipient samples but also in the donor sample, indicating that this $\mathrm{T}$ cell clone expanded in the donor for unknown reasons. It may be possible that a memory $\mathrm{T}$ cell subset could respond to a virus infection and encounter the same viral antigen in the recipient body after HSCT; however, there was a decrease and ultimate loss of this V84 monoclone together with disease recurrence and death. We also suspected that this clonally expanded $\mathrm{T}$ cell may mediate an anti-leukemia effect in the recipient, and it may have a cross response to the epitopes expressed in the leukemic $\mathrm{T}$ cells in this case. Increasing data have shown that $\gamma \delta$ T cells play a critical role in anti-tumor function. Lamb and colleagues found that the five year leukemiafree survival (LFS) and OS of acute leukemia patients with increased $\gamma \delta \mathrm{T}$ cells after HSCT was significantly higher compared with those with normal/decreased $\gamma \delta \mathrm{T}$ cells. Meanwhile, this group also demonstrated in vitro that original donor $\gamma \delta \mathrm{T}$ cells are less likely to mediated GvHD effects [21-23]. Most recently, V $\delta 1$ and V $\delta 2 \mathrm{~T}$ cell clones expanded in vivo have been demonstrated to efficiently lyse primary lymphoid and myeloid blasts in patients who received HLA-haploidentical transplantation (haplo-HSCT) [24-27]. These results may support that the donor derived V $84 \mathrm{~T}$ cell clone we identified here may be specific to any T-ALL antigen and work efficiently for lysing T-ALL blasts. For confirming the function of $\mathrm{V} \delta 4 \mathrm{~T}$ cells, TCR $\gamma \delta$ gene could be cloned from this $\mathrm{V} \delta 4$ $\mathrm{T}$ cells and transferred to healthy $\mathrm{T}$ cells to detect the specific cytotoxicity $[28,29]$. If the anti-leukemia effect could be confirmed, such clonally expanded V $\delta 4 \mathrm{~T}$ cells in this case may be considered as specific DLI to avoid GvHD development. In addition, we observed that the V84 expression level in the PBMC significantly increased, while no in the bone marrow, the reason may be due to the difference of $\mathrm{T}$ cell numbers, the homing of donor $\mathrm{T}$ cells and the different microenvironment, it may be interesting to farther investigation. However, even oligoclonal V $83 \mathrm{~T}$ cells were identified, it seemed more complex to address. Because, the clonally expanded V $\delta 3 \mathrm{~T}$ cells with $508 \mathrm{bp}$ identified in both donor and recipient samples obviously originated from the donor, and it is possible that possesses a specific anti-leukemia function or alternative functions. While the V $\delta 3 \mathrm{~T}$ cell clone with 526 bp detected only in the patient sample pre-HSCT (RE1) and several samples after-HSCT might be a minor leukemic clone in this case, because it appeared at the time of pre-HSCT and MRD but was more obvious and monoclonal when the patient underwent RE2 and RE3. However, the function of the clonally expanded $\mathrm{V} \delta 3$ requires further confirmation.

In conclusion, we reported a T-ALL case who experienced three relapses and received HSCT and DLI with an OS time lasting for more than seven years, persistent clonally expanded $\mathrm{V} \delta 4 \mathrm{~T}$ cells may hint to a relatively better outcome for this case. However, the
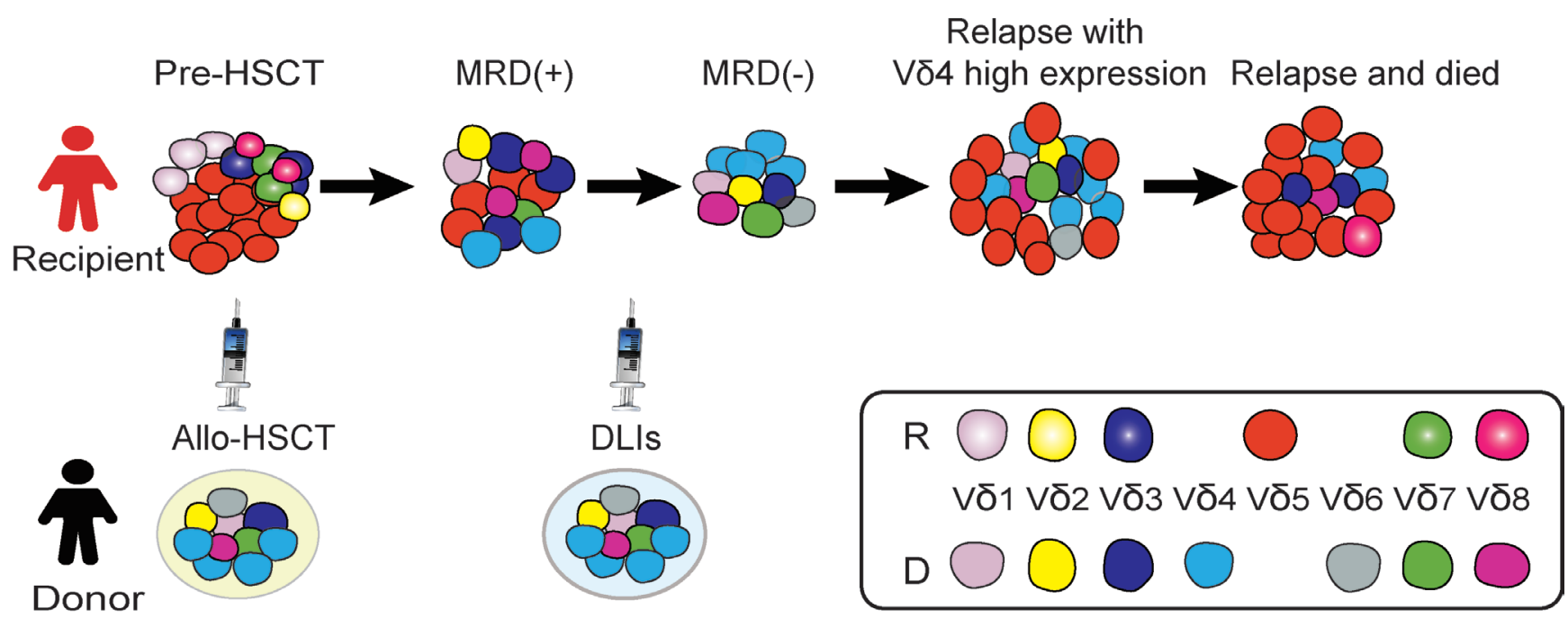

Figure 5: A schematic diagram of $\gamma \delta \boldsymbol{T}$ cell and leukemic clone evolution in the case with T-ALL. The red cells represent V55 leukemic clone identified in this case and not exist in the donor sample, this leukemic clone nearly undetectable when the patient achieved CR with $0.14 \%$ MRD detected by FCM, while it appeared again when the third time of disease relapse; the sky-blue cells represent V $\delta 4$ monoclone T cell detected in the donor sample and the same V $\delta 4 \mathrm{~T}$ cell clone expanded in the recipient samples post-HSCT; the cells fill with gradient dark blue represent $526 \mathrm{bp} \mathrm{V \delta 3} \mathrm{T} \mathrm{cell} \mathrm{clone} \mathrm{detected} \mathrm{in} \mathrm{the} \mathrm{patient} \mathrm{sample} \mathrm{pre-HSCT} \mathrm{(RE1)} \mathrm{and} \mathrm{several} \mathrm{samples}$ after-HSCT, especially in the recipient samples collected in RE3, but not exist in the donor sample, while, cells fill with dark blue (without gradient) represent the 508 bp clonally expanded V $\delta 3$ T cells identified in the donor sample which also can be detected as a monoclone in the recipient samples in 117,135 and 142 weeks post-HSCT. 
genetic or epigenetic alteration as well as the tumor microenvironment may be the important factors to influence the outcome and survival [30,31], for example, low expression of T-cell transcription factor BCL11b predicts inferior survival in adult standard risk T-ALL patients, our previous study showed overexpression of $B C L 11 \mathrm{~b}$ in T-ALL samples including sample from this case [32], is this one of the possible role in this case with unusually long survival, it remains an open question. Although this T-ALL case lived much longer than most relapse T-ALL patients, disease recurrence still indicates a worse final outcome even for cases of late relapse (relapses after 17 years have been reported), and their prognosis after relapse may be poor as reported [33-35]. Therefore, it is important to maintain the first complete remission as long as possible. In addition, $\gamma \delta \mathrm{T}$ cell repertoire as well as TCR $\alpha \beta$ analysis is an important tool for monitoring malignant $\mathrm{T}$ cell clone and detecting MRD, while donor derived $\gamma \delta \mathrm{T}$ cells might have potential GVL effects without significant GvHD effects. Recently, a new subtype of memory $T$ cells, stem cell memory $T$ $\left(\mathrm{T}_{\mathrm{SCM}}\right)$ cells, was shown to be associated with superior $\mathrm{T}$ cell engraftment, persistence, and anti-tumor immunity in HSCT. Monitoring human $\mathrm{T}_{\mathrm{SCM}}$ cells may help to evaluate the immune status for such patients $[36,37]$.

\section{MATERIALS AND METHODS}

\section{Sample preparation}

The patient and donor peripheral blood (PB) samples were collected in EDTA-containing collection tubes, and PB mononuclear cells (PBMCs) were separated using the Ficoll-Hypaque gradient centrifugation method. RNA was extracted using TRIzol (Invitrogen, Carlsbad, CA, USA), and it was then reverse-transcribed into firststrand cDNA for TCR repertoire amplification using random hexamer primers and the High Capacity cDNA Reverse Transcription kit (ABI, Carlsbad, CA, USA) according to the manufacturer's instructions. This study was approved by the Ethics Committee of the Medical School of JINAN University of Guangdong Province in China, and all procedures were conducted according to the guidelines of the Medical Ethics Committees of the health bureau of the Guangdong Province of China.

\section{RT-PCR for TCR $V \gamma$ and $V \delta$ subfamily member amplification}

Three sense TCR V $\gamma$ primers and a single $\mathrm{C} \gamma$ reverse primer, or eight TCR V $\delta$ sense primers and a single $C \delta$ primer were used in an unlabeled PCR to amplify the TCR $\mathrm{V} \gamma$ and $\mathrm{V} \delta$ subfamilies, respectively. PCR was performed as described in our previous report [38]. Aliquots of the cDNA $(1 \mu \mathrm{l})$ were amplified in $20 \mu \mathrm{l}$ with 1 of the $3 \mathrm{~V} \gamma$ primers with a $\mathrm{C} \gamma$ primer or 1 of the $8 \mathrm{~V} \delta$ primers with a $\mathrm{C} \delta$ primer. The final mixture contained $0.5 \mu \mathrm{M}$ sense and antisense primer, $0.1 \mathrm{mM}$ dNTP, $1.5 \mathrm{mM} \mathrm{MgCl}, 1 \times$ PCR buffer and $1.25 \mathrm{U}$ Taq polymerase (Promega, USA). The amplification was performed in a DNA thermal cycler (BioMetra, Germany) with a 3 min denaturation at $94^{\circ} \mathrm{C}$ and 40 PCR cycles. Each cycle consisted of $94^{\circ} \mathrm{C}$ for 1 $\min , 60^{\circ} \mathrm{C}$ for $1 \mathrm{~min}$ and $72^{\circ} \mathrm{C}$ for $1 \mathrm{~min}$ with a final $7 \mathrm{~min}$ elongation at $72^{\circ} \mathrm{C}$. All PCR products were analyzed in a $1.5 \%$ agarose gel stained with ethidium bromide and then stored at $4^{\circ} \mathrm{C}$ prior to GeneScan analysis.

\section{GeneScan analysis for TCR $V \gamma$ and $V \delta$ subfamily clonality}

Positively expressed and unlabeled PCR products $(3 \mu \mathrm{l})$ were subjected to a cycle of a runoff reaction with a fluorophore-labeled $\mathrm{C} \gamma$-FAM or $\mathrm{C} \delta$-FAM primer. The labeled runoff PCR products $(2 \mu \mathrm{l})$ were heat denatured at $94^{\circ} \mathrm{C}$ for 4 min with $9.5 \mu \mathrm{l}$ formamide (Hi-Di Formamide, ABI, USA) and $0.5 \mu \mathrm{l}$ Size Standards (GenenScan-500LIZ ${ }^{\text {TM }}$ PerkinElmer, ABI). The samples were then loaded in a 310 POP-4TM gel (Performance Optimized Polymer-4, ABI, USA) and resolved by electrophoresis with a 310 DNA sequencer (ABI, Perkin Elmer) for size and fluorescence intensity analysis using GeneScan software [39-41].

\section{ACKNOWLEDGMENTS}

We are very grateful to Dr. Shannon T. Bailey for the article editing.

\section{CONFLICTS OF INTEREST}

The authors declare that they have no competing interests.

\section{GRANT SUPPORT}

This study was supported by grants from the National Natural Science Foundation of China (Nos. 91129720 and 81270604), the Guangdong Science \& Technology Project (No. 2015A050502029), the Guangdong Provincial Basic Research Program (No. 2015B020227003) and the Guangzhou Science and Technology Project Foundation (201510010211).

\section{REFERENCES}

1. Roti G and Stegmaier K. New Approaches to Target T-ALL. Front Oncol. 2014; 4:170. 
2. Poon LM, Hamdi A, Saliba R, Rondon G, Ledesma C, Kendrick M, Qazilbash M, Hosing C, Jones RB, Popat UR, Nieto Y, Alousi A, Ciurea S, et al. Outcomes of adults with acute lymphoblastic leukemia relapsing after allogeneic hematopoietic stem cell transplantation. Biol Blood Marrow Transplant. 2013; 19:1059-64.

3. Spyridonidis A, Labopin M, Schmid C, Volin L, YakoubAgha I, Stadler M, Milpied N, Socie G, Browne P, Lenhoff S, Sanz MA, Aljurf M, Mohty M, et al. Outcomes and prognostic factors of adults with acute lymphoblastic leukemia who relapse after allogeneic hematopoietic cell transplantation. An analysis on behalf of the Acute Leukemia Working Party of EBMT. Leukemia. 2012; 26:1211-7.

4. Ruutu T, Gratwohl A, de Witte T, Afanasyev B, Apperley J, Bacigalupo A, Dazzi F, Dreger P, Duarte R, Finke J, Garderet L, Greinix H, Holler E, et al. Prophylaxis and treatment of GVHD: EBMT-ELN working group recommendations for a standardized practice. Bone Marrow Transplant. 2014; 49:168-73.

5. Pui $\mathrm{CH}$. Central nervous system disease in acute lymphoblastic leukemia: prophylaxis and treatment. Hematology Am Soc Hematol Educ Program. 2006:142-6.

6. Chen S, Huang X, Zheng H, Geng S, Wu X, Yang L, Weng $\mathrm{J}, \mathrm{Du} \mathrm{X}$ and Li Y. The evolution of malignant and reactive gammadelta $+\mathrm{T}$ cell clones in a relapse T-ALL case after allogeneic stem cell transplantation. Mol Cancer. 2013; $12: 73$.

7. Fielding AK, Richards SM, Chopra R, Lazarus HM, Litzow MR, Buck G, Durrant IJ, Luger SM, Marks DI, Franklin IM, McMillan AK, Tallman MS, Rowe JM, et al. Outcome of 609 adults after relapse of acute lymphoblastic leukemia (ALL); an MRC UKALL12/ECOG 2993 study. Blood. 2007; 109:944-50.

8. Tavernier E, Boiron JM, Huguet F, Bradstock K, Vey N, Kovacsovics T, Delannoy A, Fegueux N, Fenaux P, Stamatoullas A, Tournilhac O, Buzyn A, Reman O, et al. Outcome of treatment after first relapse in adults with acute lymphoblastic leukemia initially treated by the LALA-94 trial. Leukemia. 2007; 21:1907-14.

9. Marks DI, Paietta EM, Moorman AV, Richards SM, Buck G, DeWald G, Ferrando A, Fielding AK, Goldstone AH, Ketterling RP, Litzow MR, Luger SM, McMillan AK, et al. T-cell acute lymphoblastic leukemia in adults: clinical features, immunophenotype, cytogenetics, and outcome from the large randomized prospective trial (UKALL XII/ ECOG 2993). Blood. 2009; 114:5136-45.

10. Pui $\mathrm{CH}$ and Evans WE. Treatment of acute lymphoblastic leukemia. N Engl J Med. 2006; 354:166-78.

11. Huo JS, Symons HJ, Robey N, Borowitz MJ, Schafer ES and Chen AR. Persistent Multiyear Control of Relapsed T-Cell Acute Lymphoblastic Leukemia With Successive Donor Lymphocyte Infusions: A Case Report. Pediatr Blood Cancer. 2016; 63:1279-82.

12. Henig I and Zuckerman T. Hematopoietic stem cell transplantation-50 years of evolution and future perspectives. Rambam Maimonides Med J. 2014; 5:e0028.

13. Czerw T, Labopin M, Schmid C, Cornelissen JJ, Chevallier P, Blaise D, Kuball J, Vigouroux S, Garban F, Lioure B, Fegueux N, Clement L, Sandstedt A, et al. High CD3+ and $\mathrm{CD} 34+$ peripheral blood stem cell grafts content is associated with increased risk of graft-versus-host disease without beneficial effect on disease control after reducedintensity conditioning allogeneic transplantation from matched unrelated donors for acute myeloid leukemia - an analysis from the Acute Leukemia Working Party of the European Society for Blood and Marrow Transplantation. Oncotarget. 2016; doi: 10.18632/oncotarget.8463.

14. Zheng H, Wang X, Ma Y, Xu B, Chen S, Yang L, Wu X, Przybylski GK, Huang S and Ye T. The TCR repertoire and relative gene expression characteristics of T-ALL cases with biclonal malignant V1 and V2 T cells. DNA and cell biology. 2014; 33:49-56.

15. Langerak AW, Wolvers-Tettero IL, van den Beemd MW, van Wering ER, Ludwig WD, Hahlen K, Necker A and van Dongen JJ. Immunophenotypic and immunogenotypic characteristics of TCRgammadelta $+\mathrm{T}$ cell acute lymphoblastic leukemia. Leukemia. 1999; 13:206-14.

16. Darlak KA, Wang Y, Li J-M, Harris WA, Giver CR, Huang $\mathrm{C}$ and Waller EK. Host bone marrow-derived IL-12 enhances donor $\mathrm{T}$ cell engraftment in a mouse model of bone marrow transplantation. J Hematol Oncol. 2014; 7:16.

17. Shi L, Chen S, Zha X, Xu Y, Xu L, Yang L, Lu Y, Zhu K and Li Y. Enhancement of the TCR Expression, Polyclonal Expansion, and Activation of T Cells from Patients with Acute Myeloid Leukemia After IL-2, IL-7, and IL-12 Induction. DNA and cell biology. 2015; 34:481-8.

18. Xiao H, Wang L-M, Luo Y, Lai X, Li C, Shi J, Tan Y, Fu S, Wang Y, Zhu N, He J, Zheng W, Yu X, et al. Mutations in epigenetic regulators are involved in acute lymphoblastic leukemia relapse following allogeneic hematopoietic stem cell transplantation. Oncotarget. 2016; 7:2696-708. doi: 10.18632/oncotarget.6259.

19. Neumann M, Vosberg S, Schlee C, Heesch S, Schwartz S, Gokbuget N, Hoelzer D, Graf A, Krebs S, Bartram I, Blum $\mathrm{H}$, Bruggemann M, Hecht J, et al. Mutational spectrum of adult T-ALL. Oncotarget. 2015; 6:2754-66. doi: 10.18632/ oncotarget.2218.

20. Karrman K, Castor A, Behrendtz M, Forestier E, Olsson L, Ehinger M, Biloglav A, Fioretos T, Paulsson K and Johansson B. Deep sequencing and SNP array analyses of pediatric T-cell acute lymphoblastic leukemia reveal NOTCH1 mutations in minor subclones and a high incidence of uniparental isodisomies affecting CDKN2A. J Hematol Oncol. 2015; 8:42.

21. Godder KT, Henslee-Downey PJ, Mehta J, Park BS, Chiang $\mathrm{KY}$, Abhyankar S and Lamb LS. Long term diseasefree survival in acute leukemia patients recovering with increased gammadelta $\mathrm{T}$ cells after partially mismatched related donor bone marrow transplantation. Bone Marrow 
Transplant. 2007; 39:751-7.

22. Meeh PF, King M, O'Brien RL, Muga S, Buckhalts P, Neuberg R and Lamb LS, Jr. Characterization of the gammadelta $\mathrm{T}$ cell response to acute leukemia. Cancer Immunol Immunother. 2006; 55:1072-80

23. Lamb LS Jr, Musk P, Ye Z, van Rhee F, Geier SS, Tong JJ, King KM and Henslee-Downey PJ. Human gammadelta(+) $\mathrm{T}$ lymphocytes have in vitro graft vs leukemia activity in the absence of an allogeneic response. Bone Marrow Transplant. 2001; 27:601-6.

24. Airoldi I, Bertaina A, Prigione I, Zorzoli A, Pagliara D, Cocco C, Meazza R, Loiacono F, Lucarelli B, Bernardo ME, Barbarito G, Pende D, Moretta A, et al. T-cell reconstitution after HLA-haploidentical hematopoietic transplantation depleted of TCR-+/CD19+ lymphocytes. Blood. 2015; 125:2349-58.

25. Kobayashi $\mathrm{H}$ and Tanaka $\mathrm{Y}$. T Cell Immunotherapy-A Review. Pharmaceuticals (Basel). 2015; 8:40-61.

26. Wilhelm M, Smetak M, Schaefer-Eckart K, Kimmel B, Birkmann J, Einsele H and Kunzmann V. Successful adoptive transfer and in vivo expansion of haploidentical gammadelta T cells. J Transl Med. 2014; 12:45.

27. Claret EJ, Alyea EP, Orsini E, Pickett CC, Collins H, Wang Y, Neuberg D, Soiffer RJ and Ritz J. Characterization of T cell repertoire in patients with graft-versus-leukemia after donor lymphocyte infusion. J Clin Invest. 1997; 100:85566.

28. Knies D, Klobuch S, Xue SA, Birtel M, Echchannaoui H, Yildiz O, Omokoko T, Guillaume P, Romero P, Stauss H, Sahin U, Herr W, Theobald M, et al. An optimized single chain TCR scaffold relying on the assembly with the native $\mathrm{CD} 3$-complex prevents residual mispairing with endogenous TCRs in human T-cells. Oncotarget. 2016; doi: 10.18632/oncotarget.8385.

29. Legut M, Cole DK and Sewell AK. The promise of T cells and the $\mathrm{T}$ cell receptor for cancer immunotherapy. Cell Mol Immunol. 2015; 12:656-68.

30. Bartram I, Gökbuget N, Schlee C, Heesch S, Fransecky L, Schwartz S, Stuhlmann R, Schäfer-Eckhart K, Starck $\mathrm{M}$ and Reichle A. Low expression of T-cell transcription factor BCL11b predicts inferior survival in adult standard risk T-cell acute lymphoblastic leukemia patients. Journal of hematology \& oncology. 2014; 7:1-10.
31. Ma S, Shi Y, Pang Y, Dong F, Cheng H, Hao S, Xu J, Zhu $\mathrm{X}$, Yuan $\mathrm{W}$ and Cheng T. Notch1-induced T cell leukemia can be potentiated by microenvironmental cues in the spleen. J Hematol Oncol. 2014; 7:71.

32. Huang X, Chen S, Shen Q, Yang L, Li B, Zhong L, Geng $\mathrm{S}, \mathrm{Du} \mathrm{X}$ and Li Y. Analysis of the expression pattern of the BCL11B gene and its relatives in patients with T-cell acute lymphoblastic leukemia. J Hematol Oncol. 2010; 3:44.

33. Frost L, Goodeve A, Wilson G, Peake I, Barker H and Vora A. Clonal stability in late-relapsing childhood lymphoblastic leukaemia. Br J Haematol. 1997; 98:992-4.

34. Wyld PJ and Lilleyman JS. Late relapse after presumed cure of childhood lymphoblastic leukaemia. Lancet. 1981; 2:86.

35. Feldman F and Tan CV. Acute leukemia-relapse after prolonged remission. J Pediatr. 1970; 76:926-7.

36. Roberto A, Castagna L, Zanon V, Bramanti S, Crocchiolo R, McLaren JE, Gandolfi S, Tentorio P, Sarina B and Timofeeva I. Role of naive-derived T memory stem cells in $\mathrm{T}$-cell reconstitution following allogeneic transplantation. Blood. 2015; 125:2855-64.

37. Xu L, Zhang Y, Luo G and Li Y. The roles of stem cell memory $T$ cells in hematological malignancies. Journal of hematology \& oncology. 2015; 8:1-5.

38. Casorati G, De Libero G, Lanzavecchia A and Migone N. Molecular analysis of human gamma/delta+ clones from thymus and peripheral blood. J Exp Med. 1989; 170:152135.

39. Triebel F and Hercend T. Subpopulations of human peripheral T gamma delta lymphocytes. Immunol Today. 1989; 10:186-8.

40. Borst J, Wicherink A, Van Dongen JJ, De Vries E, Comans-Bitter WM, Wassenaar F and Van Den Elsen P. Non-random expression of $\mathrm{T}$ cell receptor gamma and delta variable gene segments in functional $\mathrm{T}$ lymphocyte clones from human peripheral blood. Eur J Immunol. 1989; 19:1559-68.

41. Xu L, Lu Y, Lai J, Yu W, Zhang Y, Jin Z, Xu Y, Chen J, Zha X, Chen S, Yang L and Li Y. Characteristics of the TCR Vbeta repertoire in imatinib-resistant chronic myeloid leukemia patients with ABL mutations. Sci China Life Sci. 2015; 58:1276-81. 